\title{
Like artificial trees? The effect of framing by natural analogy on public perceptions of geoengineering
}

\author{
Adam Corner • Nick Pidgeon
}

Received: 7 January 2014 / Accepted: 4 May 2014 / Published online: 17 May 2014

C) The Author(s) 2014. This article is published with open access at Springerlink.com

\begin{abstract}
The linguistic frames used to describe new areas of science and technology can have a powerful effect on the way that those technologies are perceived by the general public. As geoengineering continues to attract scholarly and policy interest, a number of frames have emerged in the scientific, political and media discourse. In the current paper, we provide an empirical test of one of the most prevalent framing devices: describing geoengineering technologies by analogy to natural processes. In an online experiment with members of the UK public, participants who read a description of geoengineering technologies as analogous to natural processes were more likely to support geoengineering as a response to climate change. In addition, participants' views about the relationship between geoengineering and nature strongly predicted support for geoengineering. Our findings suggest that communicators should be cautious when using natural analogies to communicate about geoengineering with the general public, as frame choice is likely to influence public attitudes and potentially convey undue positivity.
\end{abstract}

\section{Introduction}

\subsection{Geoengineering \& 'the public'}

Over the past 15 years, geoengineering - the deliberate large-scale manipulation of the planetary environment to counteract anthropogenic climate change- has gradually started to attract scholarly and policy interest (Belter and Seidel 2013). Geoengineering refers to a wide range of proposals to use large-scale technologies to slow down and/or reverse the effects of

This article is part of a special issue on "Multidisciplinary perspectives on climate ethics" with guest editors Marco Grasso and Ezra M. Markowitz.

Electronic supplementary material The online version of this article (doi:10.1007/s10584-014-1148-6) contains supplementary material, which is available to authorized users.

A. Corner $(\bowtie) \cdot$ N. Pidgeon

School of Psychology, Cardiff University, 70 Park Place, CF10 3AT Cardiff, UK

e-mail: corneraj@cardiff.ac.uk

A. Corner $\cdot$ N. Pidgeon

Tyndall Centre for Climate Change Research, Cardiff, UK 
anthropogenic climate change (Royal Society 2009). The only link between them is that they all have the potential to be deployed in order to control or alter the Earth's climate.

Very broadly, geoengineering technologies fall into two categories: proposals to remove a proportion of Carbon Dioxide from the atmosphere (Carbon Dioxide Removal-CDR) and proposals to reflect a proportion of sunlight away from the Earth, thereby lowering global temperatures (Solar Radiation Management-SRM). The technologies implicated in these proposals vary enormously on many important dimensions. Some are well-understood but would be ineffectual unless deployed on an incredibly large scale (e.g. reforestation programmes to absorb carbon dioxide). Others are considered to be effective at reducing global temperatures but carry significant risks in terms of unintended consequences (e.g. the releasing of reflective sulphate particles into the stratosphere to reflect sunlight-Royal Society 2009).

Research investigating technical questions about the feasibility and safety of putative geoengineering technologies has started to proliferate (Belter and Seidel 2013; Vaughan and Lenton 2011). The social and ethical dimensions of geoengineering have begun to be explored by philosophers (Gardiner 2011; Hamilton 2013) and social scientists (Corner and Pidgeon 2010). And there is a relatively small (but growing) body of research which documents public perceptions of geoengineering (Corner et al. 2012 - and see the following section for a selective overview).

In addition, the very concept of 'geoengineering' has been critically appraised and challenged as a useful category or label (Bellamy et al. 2013; Boucher et al. 2014; Cairns 2013; Heyward 2013). Some have argued that geoengineering ought not be so strictly distinguished from mitigation and adaptation policies, when in fact there are considerable conceptual overlaps between the three approaches (Boucher et al. 2014; Heyward 2013; Markusson et al. 2013a). Cairns (2013) suggested that the term geoengineering is sufficiently ambiguous that it permits different actors to pursue multiple divergent interpretations (Cairns 2013). Others have argued that, given the diversity of ideas covered by the term, an undue focus has been placed on a relatively small number of technologies and that this is 'closing down' the debate about what geoengineering means (Bellamy et al. 2013). At the very least, geoengineering as a linguistic object is heterogeneous (Markusson et al. 2013a), there are multiple and divergent framings of geoengineering already in existence, and these framings are likely to impact on public perceptions in very different ways. In fact, geoengineering is perhaps most usefully conceived of not as a technology or even a set of technologies, but as a discursive phenomenon, the bounds of which are continually being negotiated (Cairns 2013; Sikka 2012).

In the same way that geoengineering is a contested term, the idea of engaging the public around new and emerging areas of technology like geoengineering is not unproblematic (Macnaghten 2010; Stirling 2008). The concept of engaging a singular 'public' offers a useful shorthand for thinking about the web of relations between socio-technical development and the different 'publics' that in reality exist, but it does not reflect its complexity or plurality (Hauser 1999). In particular, although for a long time it was assumed that engaging publics on new areas of science and technology was best characterised as 'DEAD' (Decide Educate Announce and Defend-Hartz-Karp 2007), it is now widely agreed that non-experts do not have a 'deficit' of knowledge that requires 'filling' in order for their attitudes to fall in line with those of scientists. Indeed, persuading the public of the worth of a new technology is not generally considered to be an appropriate aim of engagement (Fiorino 1990; Stirling 2008).

Instead, non-experts bring a variety of considerations to bear including value-based concerns often deemed unimportant or trivial by scientists and other expert commentators, but which are likely to prove significant for laypeople (Pidgeon et al. 2013). When public engagement occurs before significant research and development into a new technology has 
begun and prior to entrenched attitudes or social representations becoming established, it is typically referred to as 'upstream' (Rogers-Hayden and Pidgeon 2007; Pidgeon et al. 2009; Wilsdon and Willis 2004). Relevant 'lay' questions at an upstream phase in a technology's development might include asking what a technology is for, who is likely to own or profit from it, or who will be responsible if things go wrong. Geoengineering technologies are clearly at an upstream stage, but as Stilgoe (2011) has argued, it is the concept of geoengineering and the imputed intent to deploy it (rather than any particular technology downstream) that is the focus of much current engagement.

The general public are more accurately conceived of not as a static, monolithic entity but a plurality of groups with a range of motivations and identities who can offer perspectives and observations that go beyond a 'narrow' framing of the risks and benefits of a new technology (Stirling 2008). In the context of geoengineering, this is reflected in the prevalence of 'participatory' research which permits competing or dissonant perspectives to be explored (e.g., Pidgeon et al. 2013). As part of a growing commitment to the idea of 'responsible innovation' among science-policy stakeholders, there is a great deal of interest in ensuring that public views and values are incorporated in relevant science-policy decision making (Parkhill et al. 2013; Stilgoe et al. 2014).

In the following section we outline findings from both participatory and experimental/ survey studies and attempt to draw some relevant conclusions about what members of the public currently think about the nebulous concept of geoengineering — while acknowledging that the notion of a singular 'public' is not without issue.

\subsection{Perceptions of geoengineering}

Multiple factors impact on public attitudes towards new and emerging areas of science and technology. Based on analyses of public perceptions of issues such as GM crops, or nanotechnologies, concerns about safety, corporate and governmental trustworthiness, the distribution of potential benefits, and the unintended (or unforeseen) consequences of new technologies all play a role in determining public perceptions of risk (Corner and Pidgeon 2012; Kearnes et al. 2006; Walls et al. 2005). In addition, there are a range of generic factors that determine people's perceptions of environmental and technological risks - such as whether there is a chance of 'catastrophic' disaster; whether a risk seems controllable, and (as we discuss in more detail below) whether a risk appears to be 'natural' or 'artificial' (Slovic 2000).

Geoengineering is no different in this regard, and when members of the public are introduced to the topic of geoengineering in structured discussion groups and deliberative workshops, a range of nuanced views and opinions are observed. In particular, people tend to be more favourable towards CDM technologies, fearful of the unintended consequences of climatic intervention and wary of the possibility that the risks of geoengineering will be greater than those of the problem it is designed to solve (Corner et al. 2013; Macnaghten and Szerszynski 2013). Reflecting the importance of concerns about 'catastrophe' for risk perceptions in general, Bellamy et al. (2012) found that the two most popular ways of conceptualising geoengineering were as a climatic emergency, and as a 'plan B' response to insufficient mitigation. Perceptions of geoengineering are partly a function of the existing social, political, and moral views that people hold: individuals with more individualistic views are more likely to be more favourable (Kahan et al. 2012). And although there appears to be limited support for the notion of careful, incremental and transparent research into geoengineering (Pidgeon et al. 2013), most people have serious reservations about ever deploying SRM technologies in particular (Macnaghten \& Szerszynski, 2013; Pidgeon et al. 2013). 
However, because most of the putative technologies included in the category 'geoengineering' do not yet (and may never) exist, most members of the public do not have strongly held or entrenched views (Corner et al. 2012), and public awareness of geoengineering is still very low (Corner et al. 2012). Typically, surveys of public opinion find that less than $5 \%$ of respondents claim any substantive knowledge about the issue, although a somewhat higher number are able to offer a broadly accurate definition of the term 'climate engineering' (Mercer et al. 2011). There is significant interest in trying to understand the factors that will influence public views as awareness about the subject grows, and one way that this has been pursued is through analyses of the way that early media reports have framed geoengineering.

\subsection{Framing geoengineering}

A growing body of literature has examined the emerging language, metaphors and frames used in news articles to describe geoengineering. Early media coverage is of particular interest, as initial media frames are sometimes described as 'sticky', meaning that after a dominant framing of the issue has settled, further framings are more difficult to introduce (Nisbet et al. 2003). Nerlich and Jaspal (2012) analysed a large corpus of news coverage from the 1980s to 2010, and found that it was dominated by three overarching metaphors: the planet as a body that might be repaired, fixed or healed; the planet as a machine; and the planet as a patient/addict. Within each of these metaphors are assumptions - or social 'imaginaries' that speak to the way in which humans and the natural world are related. Nerlich and Jaspal argued that the language of active scientists - as key communicators about geoengineering - was shaping the way that geoengineering was being reported and debated (see also Luokkanen et al. 2013).

Scholte et al. (2013) investigated how newspaper frames on geoengineering had evolved over time, from 2002-2011. Their analysis emphasised that while initial media coverage focused on the technical aspects of geoengineering - often describing geoengineering as a 'technofix' (whether positively or negatively) _ frames emphasising more ambivalent positions emerged later. These tended to focus on concerns about conflict and governance, and later still, on geoengineering as a 'pragmatic' response to climate change (given other policy failures). Similarly, Porter and Hulme (2013) analysed geoengineering frames in the UK news media, and found that underlying assumptions about the nature-human relationship were an important influence on frame construction - whether embodied in framings of technological innovation, societal risk, security or morality. Media coverage largely opposed to geoengineering tended to utilise a conception of nature as all-powerful, rendering human intervention futile. Broadly supportive media coverage, by comparison, tended to conceptualise nature as something amenable to human will-with human incursions into the 'natural' domain viewed as indications of societal progress.

However, there have been no attempts to investigate the framing of geoengineering experimentally, which is surprising given the prevalence of this form of research around other contentious or emerging topics. For subjects as diverse as communicating climate change (e.g., Bain et al. 2012; Morton et al. 2011), the strategies of social movements (Benford and Snow 2000), and the perceived risks and benefits of nanotechnologies (Cobb 2005), the controlled, experimental investigation of differing framing devices has been a rich source of knowledge. In the current study, we seek to remedy the lack of experimental framing research on geoengineering, by focusing on one prevalent frame in particularthe comparison of certain geoengineering technologies to natural processes. Before we introduce the design of the current research, we first outline the relationship between 
perceptions of geoengineering and perceptions of nature, which has played a particularly central role so far in the geoengineering discourse.

\subsection{Geoengineering and nature}

There are multiple examples of geoengineering technologies being described by analogy to natural processes and concepts (in both popular and academic publications). In particular, stratospheric aerosol engineering is often described as operating in the same way that a volcano does (e.g., by the Editor of Nature, Daniel Cressy ${ }^{1}$ ), while chemical $\mathrm{CO} 2$ removal is frequently described (and depicted) as being analogous to the removal of $\mathrm{CO} 2$ from the atmosphere by trees (e.g., Ipsos MORI, 2010). A Google search of the term 'geoengineering' with 'artificial volcano' returns more than 4,000 hits. $^{2}$

The volcano analogy is not simply a useful communicative technique for scientists and others who want to explain how stratospheric aerosol injection would work. The inspiration for stratospheric aerosol engineering is the observed effect of volcanic eruptions that have taken place, producing temporary but not entirely localised cooling effects. Volcanic eruptions provide evidence that stratospheric sulphate particle injection leads to reductions in globallyaveraged surface temperatures (e.g., Pope et al. 2012). And, although chemical carbon capture projects were not designed with the specific aim of imitating the process that trees and other vegetation use to remove $\mathrm{CO} 2$ from the atmosphere, there is a clear and intuitive analogy. The use of volcanos and trees as natural analogies for geoengineering technologies is not necessarily 'wrong' or inappropriate. But while these characterisations might be technically accurate, they also provide a powerful framing: that the way to think about these technologies is by analogy to existing 'natural' processes.

In a series of structured discussion groups conducted with members of the public in 2010, titled 'Experiment Earth?' (Ipsos MORI, 2010), some illuminating insights into what 'informed' public opinion on geoengineering may look like were identified (see also Macnaghten and Szerszynski 2013; Pidgeon et al. 2013). Participants raised serious concerns about the safety of SRM technologies, and a strong preference for more conventional, mitigation options over geoengineering techniques tended to be expressed. Perceived 'naturalness' (and the extent to which different geoengineering technologies were perceived as 'interfering' in nature) was an important determinant of public perceptions (see also Macnaghten and Szerszynski 2013). Certain geoengineering proposals - like the use of 'biochar', or afforestation - were seen as more natural, and therefore more acceptable, than others (such as the use of mirrors in space to reflect sunlight), tallying with survey data suggesting that messing with nature is a prominent public concern (Carr et al. 2012).

Reflecting on the Experiment Earth? findings, however, Corner et al. (2012) cautioned against interpreting too simplistically the idea that some geoengineering technologies were more 'natural' than others, as the framing of the different technologies by the group facilitators may have unintentionally introduced this idea to participants. The analogies used to describe certain technologies alluded very strongly to a 'naturalness', while others did not. In particular, chemical vents for capturing carbon dioxide from the air were repeatedly described as 'artificial trees', while the release of sulphur particles into the stratosphere was reported to participants as being 'no different to a volcano'. Notably, support for the chemical capture of

\footnotetext{
${ }^{1}$ Daniel Cressy reports on the cancellation of the UK's 'SPICE' testbed: http://www.nature.com/news/ geoengineering-experiment-cancelled-amid-patent-row-1.10645

${ }^{2}$ Google search of the terms 'geoengineering' and 'artificial volcano' conducted on 15/04/14 and returned 4,370 results.
} 
carbon dioxide increased during the deliberations, and stratospheric aerosol injection was among the most popular SRM technologies (Ipsos MORI, 2010).

Further evidence that ideas about naturalness are likely to shape attitudes towards geoengineering was provided by Corner et al. (2013) in a qualitative research study of members of the UK public. A series of public discussion groups (termed deliberative workshops) were conducted in 2012. One of the strongest themes to emerge was the question of whether geoengineering represented an unprecedented intervention into nature (and what the social and ethical consequences of this might be). Some participants argued that the appropriate role for human technologies was to work in harmony with nature - and that any attempt to control the climate was therefore wrong. Others countered that this was naive, or even hypocritical, suggesting that humans have "messed with nature" in the past when it has suited us, and that geoengineering could represent a way of giving nature a "helping hand" in fixing the problem of climate change. There was no consensus on what constituted the natural, or whether geoengineering was an inherently good or bad thing with regards to our relationship to nature. But the "messing with nature" theme proved fertile ground for discussion.

Geoengineering is certainly not the first technology to provoke strong contestation about the relationship between humans and nature (Macnaghten and Urry 1998), but it is not difficult to see why concerns about 'messing with nature' and the issue of naturalness might play a central role in shaping public perceptions of geoengineering (see also Hamilton 2013; Preston 2012). However, there has not yet been a study yet that has sought to directly compare and measure the impact that framing geoengineering by analogy to natural processes has on public perceptions.

In the current research, therefore, we conducted an experiment with an online sample of the general public to test the impact of framing geoengineering by analogy to natural processes on public views about geoengineering.

\section{Method}

\subsection{Participants}

412 UK participants were recruited using the online market research company Research Now during the summer of 2013. Nationally representative quotas were obtained for key demographic variables including age $(M=46.45)$, gender (58 \% female), socio-economic group (calculated on the basis of the vocation of the Chief Income Earner in their household), ethnicity (92\% White; $4 \%$ Asian the next largest group) and geographical region. $25 \%$ indicated that they would vote Labour at the next General Election (21\% Conservative $18 \%$ UKIP, $10 \%$ Lib Dem and $6 \%$ Green Party), indicating a spread of political views. $8 \%$ reported that they were a member of an environmental organisation.

\subsection{Design, materials \& procedure}

After completing an online consent form, participants answered a series of demographic questions (see participant quotas described above). Next, all participants completed a widely used 12-item scale used to measure climate change scepticism (Whitmarsh 2011-see Appendix 1, Electronic Supplementary Material). All items were rated using a 5 point scale from 'strongly agree' to 'strongly disagree'. Two items relating to geoengineering knowledge were included. The first asked whether participants had heard of the term geoengineering previously ('yes' or 'no'). The second asked participants to indicate on a 5 point scale how 
much they knew about geoengineering, from 'I have not heard about geoengineering' to 'I know a great deal about geoengineering'.

Participants were then presented with a screen that was described as containing a 'factsheet' titled 'Geoengineering: a new approach for tackling climate change?', ostensibly downloaded from a (fictional) website climateinfo.org. (see Appendix 2, Electronic Supplementary Material for the full factsheets). Each factsheet contained text describing some of the expected risks of climate change and briefly outlining possible societal responses to it, including mitigation, adaptation, and a third (new) option of geoengineering. Thus, geoengineering was situated as one of three options for responding to climate change.

The penultimate paragraph of all versions of the factsheet described geoengineering as follows:

Most geoengineering technologies have not yet been developed, and so there is a great deal of uncertainty about their risks and benefits. There are likely to be some serious risks and side effects associated with geoengineering (e.g. changes to global rainfall patterns) but they are not yet well understood.

The final paragraph of each factsheet contained a brief quote from a (fictional) expert, Professor North (described as a 'leading atmospheric scientist'). Depending on the experimental condition participants were randomly assigned to, Professor North's 'quote' was systematically varied (i.e., the framing manipulation).

In the experimental condition, two geoengineering technologies (stratospheric aerosol injection and chemical carbon dioxide removal) were described by analogy to a natural process (a volcanic eruption and a tree respectively). In a control condition, they were described using standard, formal language deployed by scientists, and no natural analogy was included. We took great care to change as few words as possible between experimental conditions, to provide as direct a comparison as possible.

Natural analogy: experimental condition

One technology that we are working on acts like an artificial tree by breathing in carbon dioxide from the atmosphere and then storing it underground. Another of our ideas is to imitate the effect of a volcano, by releasing millions of tiny, reflective particles into the highest part of our atmosphere. When a volcano erupts, there is a temporary cooling effect, because certain particles (for example sulphur) reflect sunlight. If a large number of tiny, reflective particles were sprayed into space, this would have a cooling effect on the Earth's temperature.

Standard description: control condition

One technology that we are working on involves a chemical process and large industrial machinery to remove carbon dioxide from the atmosphere and then store it underground. Another idea we have is to inject millions of tiny, reflective particles (also called aerosols) into the highest part of our atmosphere. Certain chemicals, for example sulphur, reflect sunlight, although hydrogen sulphide would also have a similar effect. If a large number of tiny, reflective particles were sprayed into space, this would have a cooling effect on the Earth's temperature. ${ }^{3}$

Following the factsheet, we included two sets of dependent measures.

\footnotetext{
${ }^{3}$ It should be noted that the stratosphere $(\sim 10-50 \mathrm{~km}$ above the earth's surface) is not generally understood as being 'in space'. However, this more colloquial term was used in order to reduce the technicality of the description for participants.
} 
The first set captured general views about geoengineering, including a question on geoengineering support ('To what extent would you support geoengineering as a response to climate change?'- measured on a 5 point scale from 'strongly support to 'strongly oppose'), and two other measures of attitudes towards geoengineering, both recorded on a 5 point scale from 'strongly agree' to 'strongly disagree': 'Geoengineering will help the planet more than it will hurt it' (adapted from Mercer et al. 2011) and 'The risks of geoengineering will outweigh the benefits'.

The second set of measures was adapted from Mercer et al. (2011), and the questions related specifically to the relationship between geoengineering and the natural world. All three were recorded on a 5 point scale from 'strongly agree' to 'strongly disagree': 'The Earth's temperature is too complicated to fix with one technology'; 'Geoengineering is natural'; and 'Humans should not be manipulating nature in this way'.

As value orientations play such a central role in public engagement with climate change (Corner et al. 2014) and based on existing empirical work on perceptions of geoengineering (e.g., Kahan et al. 2012), we anticipated that participants' values would also be related to their views on geoengineering. Values are typically defined as 'guiding principles in the life of a person' following Schwartz (1992), and are measured using a values inventory. Values are arranged into subsets based on extensive previous empirical and theoretical work (Schwartz 1992), and the most relevant ones for public engagement with climate change and geoengineering are those that capture 'self-enhancing' values and 'self-transcendent' values (self-transcendent values consistently predict positive engagement with climate change, while self-enhancing values negatively predict climate change engagement - Corner et al. 2014). We therefore used four items from the Schwartz (1992) values inventory which measure 'selftranscending' values and four items which measure 'self-enhancing' values to capture these opposing value orientations (see Appendix 1, Electronic Supplementary Material).

When participants had completed all the questions, they read a debriefing screen which informed them of the purpose of the experiment, explained that they had been subject to a minor deception (a fictitious website and 'expert' quotation), and provided some background information about the motivation for the study.

\section{Results}

All the predictor variable scales used in the study had sufficient inter-item reliability to be included in subsequent analyses (climate change scepticism $\alpha=0.92$; self-enhancing values $\alpha=0.66$; self-transcending values $\alpha=0.79$ ). Levels of knowledge about geoengineering were, as expected, low. Although $26 \%$ claimed to have heard of the term 'geoengineering', less than $2 \%$ said they knew a 'fair amount' or a 'great deal' about it.

Figure 1 shows the mean ratings for both sets of dependent measures by experimental condition, demonstrating a subtle but consistent pattern: framing geoengineering by analogy to natural processes produced somewhat more positive views towards geoengineering on every measure (three of the measures were negative statements about geoengineering, so lower agreement indicates greater favourability). Taking the three general measures together, however, a MANOVA identified no significant overall effect of the experimental manipulation, $p>0.05$.

Looking specifically at the 'support for geoengineering' measure (our primary dependent variable) with an ANOVA, though, we examined the effect of the experimental manipulation with levels of scepticism to establish main effects of these key variables and potential interactions. Using experimental group and level of scepticism (median split) as independent 


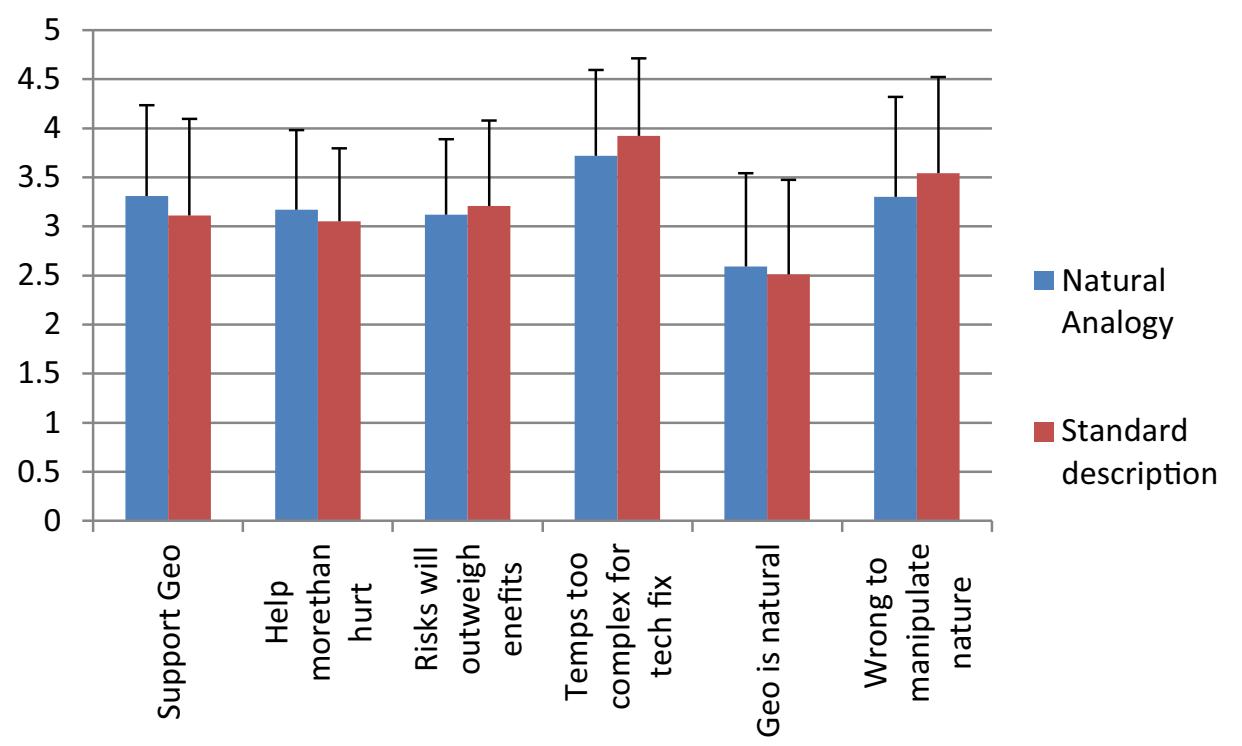

Fig. 1 Mean ratings of the six dependent measures in the study, compared across experimental conditions. Error bars represent one standard deviation

variables, a significant effect of both the experimental manipulation, $\mathrm{F}(1,408)=4.5, p<0.05$, and levels of scepticism, $\mathrm{F}(1,408)=6.5, p<0.05$, on ratings of support for geoengineering was observed. As Fig. 2 shows, support for geoengineering was particularly high among those low in scepticism, in the natural analogy condition. However, the interaction between the two terms was non-significant. In an additional separate ANOVA, there were no significant main effects of value orientation (self-transcending or self-enhancing) on ratings of geoengineering, and no interaction between either value orientation and the experimental manipulation $(p>0.05$ in all cases).

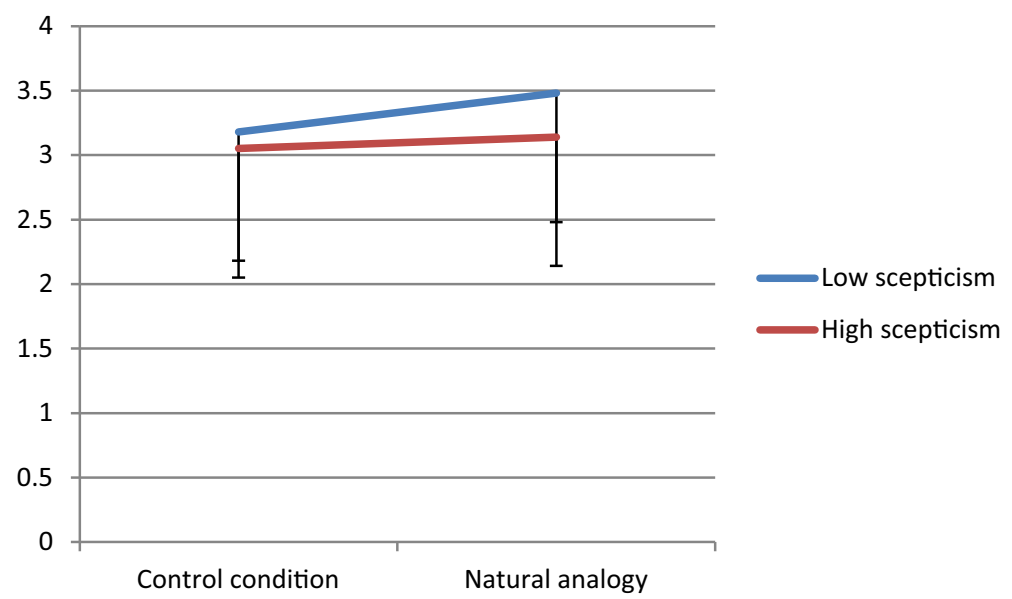

Fig. 2 Mean ratings of support for geoengineering in the control and natural analogy condition, by level of scepticism. Error bars represent one standard deviation 
Focussing again just on the 'support for geoengineering' measure, a linear regression analysis was conducted to establish the factors that predicted support for geoengineering. In addition to the experimental manipulation itself, the model included key demographic variables (gender, age and socio-economic group ${ }^{4}$ ), scepticism and value scores, geoengineering knowledge and the three 'naturalness' variables. Table 1 displays the results of the regression, with blocks of variables entered sequentially. It shows that while the experimental manipulation initially exerts a significant effect on support for geoengineering, the large majority of the variance in geoengineering support is determined by the three 'naturalness' measures.

The extent to which participants saw geoengineering as natural was the strongest positive predictor of support for geoengineering. Agreement that the Earth's climate is too complex to be fixed with one technology and that it is wrong to manipulate nature were the strongest negative predictors of support for geoengineering. When these variables were introduced into the regression, the effect of the experimental manipulation was no longer statistically significant.

Age was negatively related to support for geoengineering, but there was no relationship between gender, socio-economic status, or self-reported knowledge and geoengineering support. Scepticism about climate change was negatively related to support for geoengineering, but this relationship became non-significant when the naturalness variables were included in the model. Similarly, although self-enhancing values were a positive predictor of geoengineering support, this relationship was non-significant in the final model.

\section{Discussion}

We conducted an experiment to examine the effect of framing geoengineering technologies by analogy to natural processes, on views about geoengineering. Our central finding was that support for geoengineering was slightly_but significantly_ higher when a natural analogy was included in a description of geoengineering technologies. Furthermore, the factors that most strongly predicted support for geoengineering were three measures that captured perceptions of the relationship between geoengineering and nature. Thus, we were able to provide the first systematic evidence that framing geoengineering by analogy to natural processes is likely to produce more positive attitudes among the general public. To the extent that communicators may not wish to convey undue positivity, this finding suggests caution should be exercised if a naturalness framing is deployed.

The manipulation in the study was very subtle: less than a dozen words were altered between the two conditions (in a factsheet containing over 200 words in total). Thus, the magnitude of the differences produced by the manipulation was small — and there is a history of framing research producing experimental effects of quite limited magnitude (Druckman 2001). But if even a subtle change in language can produce a statistically significant effect, then the impact of natural analogies in everyday discourse is likely to be substantially greater. The value of the current study is in isolating and systematically comparing the effect of a naturalness framing of geoengineering. It supports existing media (Nerlich and Jaspal 2012) and qualitative analyses (Corner et al. 2013) that point to a central role for ideas about 'nature' in determining perceptions of geoengineering.

\footnotetext{
${ }^{4}$ Preliminary investigation found no clear relationship between voting intention and views on geoengineering. Rather than include voting intention as a set of dummy-coded variables in the regression, this variable has instead been omitted from current analyses.
} 
Table 1 Linear regression analysis of the factors that influence support for geoengineering as a response to climate change

\begin{tabular}{|c|c|c|c|c|c|c|c|}
\hline & Predictor variables & $\begin{array}{l}\text { Model } 1 \\
\text { (Beta) }\end{array}$ & $\begin{array}{l}\text { Model } 2 \\
\text { (Beta) }\end{array}$ & $\begin{array}{l}\text { Model } 3 \\
\text { (Beta) }\end{array}$ & $\begin{array}{l}\text { Model } 4 \\
\text { (Beta) }\end{array}$ & $\begin{array}{l}\text { Model } 5 \\
\text { (Beta) }\end{array}$ & $\begin{array}{l}\text { Model } 6 \\
\text { (Beta) }\end{array}$ \\
\hline Exp group & Natural vs. Standard & $0.103^{*}$ & $0.115^{*}$ & $0.118^{*}$ & $0.111^{*}$ & 0.049 & 0.049 \\
\hline \multirow[t]{3}{*}{ Demographics } & Gender & & 0.016 & 0.000 & 0.005 & 0.000 & 0.006 \\
\hline & Age & & $-0.218 * * *$ & $-0.195 * * *$ & $-0.183 * * *$ & $-0.119 * * *$ & $-0.117 * * *$ \\
\hline & S.E. group & & 0.008 & 0.018 & 0.015 & -0.026 & -0.025 \\
\hline Scepticism & Scepticism score & & $-0.173 * *$ & $-0.160 * * *$ & $-0.172 * * *$ & -0.065 & -0.064 \\
\hline \multirow[t]{2}{*}{ Values } & Self-enhancing & & & & $0.132 * * *$ & 0.036 & 0.037 \\
\hline & Self-transcending & & & & -0.006 & 0.073 & 0.071 \\
\hline \multirow{3}{*}{$\begin{array}{l}\text { Naturalness } \\
\text { measures }\end{array}$} & Temp complex & & & & & $-0.097^{*}$ & $-0.102^{*}$ \\
\hline & GeoNatural & & & & & $0.385^{* * *}$ & $0.382 * * *$ \\
\hline & ManipNature & & & & & $-0.299 * * *$ & $-0.298 * * *$ \\
\hline $\begin{array}{l}\text { Geoengineering } \\
\text { knowledge }\end{array}$ & & & & & & & 0.035 \\
\hline Adjusted R square & & 0.011 & 0.056 & 0.074 & 0.082 & 0.431 & 0.431 \\
\hline
\end{tabular}

Significance at $p<0.05$ is indicated by *. Significance at the $p<0.01$ level is indicated by ***

Somewhat surprisingly, age — but not gender-was negatively related to support for geoengineering. One speculative explanation is that the deeply futuristic idea of geoengineering the climate is more alien and unfamiliar to older participants. An equally plausible explanation is that older participants may have more experience of the hyperbole that often accompanies emerging technologies, and are more likely to approach the idea of a technological 'fix' to a highly complex social problem like climate change with greater cynicism. However, the finding is difficult to explain based on the current data, and future research should aim to incorporate an explicitly age-oriented focus to investigate it further.

An interesting relationship between scepticism, self-enhancing value orientations and support for geoengineering was also observed: although scepticism negatively predicted geoengineering support, participants scoring more highly on self-enhancing values were more likely to favour it (although this relationship was not significant in the regression analyses once the naturalness measures had been included). A common explanation for scepticism about climate change is that climate policies such as the regulation of industry threaten self-enhancing values and individualistic worldviews (e.g., Kahan 2012). But the current study appears to show a dissociation between scepticism and self-enhancing values in terms of support for geoengineering. This suggests that geoengineering might represent a climate policy solution that does not threaten self-enhancing values or individualistic worldviews (see also, Kahan et al. 2012). However, given the limited impact of the value-orientation items overall in our analyses, more work seems required to tease out the exact relationship between value orientations, scepticism and support for geoengineering.

Although great care was taken in creating the materials for the framing manipulation, there are methodological elements that could have been improved further. For example, while we aimed for neutrality in the language used in the control condition, the inclusion of the term 'injection' (relating to the putative mechanism for deploying stratospheric aerosols) has its own powerful metaphorical connotations. In Nerlich and Jaspal's (2012) analysis of the 
dominant metaphors in media coverage of geoengineering, the idea of the planet as a body that could be healed was prevalent. Medical terms like 'inject' are likely to prime this particular conceptual interpretation, and this may have impacted on participants' responses.

This study has only examined one popular framing device used to communicate about geoengineering - future research could focus on others, such as the idea that geoengineering is a response to a 'climatic emergency' (Markusson et al. 2013b). However, it has provided the first experimental evidence that even a subtle difference in the wording of information about geoengineering can influence subsequence judgements of favourability. If scientists, policymakers and civil society actors wish to communicate about geoengineering in a way that does not convey an unduly positive impression of what is still a highly uncertain and deeply risky technological domain, then exercising caution when using analogies to natural processes is advised.

Acknowledgments This research was conducted as part of the Integrated Assessment of Geoengineering Proposals (IAGP) grant from the Natural Environment Research Council and the Engineering and Physical Sciences Research Council (RES-066-27- 00013). The authors would like to thank Ezra Markowitz and Marco Grasso for organising the special issue and preceding workshop in 2013.

Open Access This article is distributed under the terms of the Creative Commons Attribution License which permits any use, distribution, and reproduction in any medium, provided the original author(s) and the source are credited.

\section{References}

Bain PG, Hornsey MJ, Bongiorno R, Jeffries C (2012) Promoting pro-environmental action in climate change deniers. Nat Clim Chang 2:600-603

Bellamy R, Chilvers J, Vaughan NE, Lenton TM (2012) A review of climate geoengineering appraisals. Wiley Interdiscip Rev Clim Chang 3(6). doi:10.1002/wcc.197

Bellamy R, Chilvers J, Vaughan N, Lenton T (2013) 'Opening up' geoengineering appraisal: Multi-Criteria Mapping of options for tackling climate change. Glob Environ Chang. doi:10.1016/j.gloenvcha.2013.07.011

Belter C, Seidel D (2013) A bibliometric analysis of climate geoengineering research. Wiley Interdiscip Rev Clim Chang 4:417-427

Benford RD, Snow DA (2000) Framing processes and social movements: an overview and assessment. Annu Rev Sociol 26:611-639

Boucher O et al (2014) Rethinking climate engineering categorization in the context of climate change mitigation and adaptation. WIREs Clim Chang 5:23-35

Cairns R (2013) Examining framings of geoengineering using Q methodology. Climate Geoengineering Governance Working Paper Series: 002

Carr W, Mercer A, Palmer C (2012) Public concerns about the ethics of solar radiation management. In: Preston CJ (ed) Engineering the climate: the ethics of solar radiation management. Lexington Books, Lahham, pp 169-186

Cobb M (2005) Framing effects on public opinion about nanotechnology. Sci Commun 27:221-237

Corner A, Markowitz E, Pidgeon N (2014) Public engagement with climate change: the role of human values. WIREs Clim Chang. doi:10.1002/wcc.269

Corner A, Pidgeon NF (2010) Geoengineering the climate: the social and ethical implications. Environ Sci Policy Sustain Dev 52:24-37

Corner A, Pidgeon N (2012) Nanotechnologies and upstream public engagement: dilemmas, debates \& prospects. In: Mohr J, Herr Harthorn B (eds) The social life of nanotechnology. Routledge, New York

Corner A, Pidgeon N, Parkhill K (2012) Perceptions of geoengineering: public attitudes, stakeholder perspectives $\&$ the challenge of 'upstream' engagement. Wiley Interdiscip Rev Clim Chang 3:451-466

Corner AJ, Parkhill K, Pidgeon NF, Vaughan NE (2013) Messing with nature? Exploring public perceptions of geoengineering in the UK. Glob Environ Chang. doi:10.1016/j.gloenvcha.2013.06.002

Druckman JN (2001) On the limits of framing effects: who can frame? J Polit 63(4):1041-1066

Fiorino D (1990) Citizen participation and environmental risk: a survey of institutional mechanisms. Sci Technol Hum Values 15:226-243

Gardiner SM (2011) Some early ethics of geoengineering the climate : a commentary on the values of the royal society report. Environ Values 20:163-188 
Hamilton C (2013) Earthmasters: the dawn of the age of climate engineering. Yale University Press, New Haven Hartz-Karp J (2007) How and why deliberative democracy enables co-intelligence and brings wisdom to governance. J Public Deliberation 3:1-9

Hauser G (1999) Vernacular voices: the rhetoric of publics and public spheres. University of South Carolina Press, Columbia

Heyward C (2013) Situating and abandoning geoengineering: a typology of five responses to dangerous climate change. Polit Sci Polit 46(1):23-27

Kahan D (2012) Why we are poles apart on climate change. Nature 488(7411):255

Kahan D, Jenkins-Smith H, Tarantola T, Silva CL, Braman D (2012) Geoengineering and the science communication environment: a cross-cultural experiment. Cultural Cognition Working Paper 92

Kearnes M, Grove-White R, Macnaghten P, Wilsdon J, Wynne B (2006) From bio to nano: learning lessons from the UK agricultural biotechnology controversy. Sci Cult 15(4):291-307

Luokkanen M, Huttunen S, Hildén M et al (2013) Geoengineering, news media and metaphors: framing the controversial. Public Underst Sci. doi:10.1177/0963662513475966

Macnaghten P (2010) Researching technoscientific concerns in the making: narrative structures, public responses, and emerging nanotechnologies. Environ Plan A 42:23-37

Macnaghten P, Szerszynski B (2013) Living the global social experiment: an analysis of public discourse on solar radiation management and its implications for governance. Glob Environ Chang 23:465-474

Macnaghten P, Urry J (1998) Contested natures. Sage publications, London

Markusson N et al (2013) Bounding boundaries: the construction of geoengineering on wikipedia. Climate Geoengineering Governance Working Paper Series: 005

Markusson N, Ginn F, Ghaleigh N, Scott V (2013b) 'In case of emergency press here': framing geoengineering as a response to dangerous climate change. WIREs Clim Chang. doi:10.1002/wcc.263

Mercer AM, Keith D, Sharp JD (2011) Public understanding of solar radiation management. Environ Res Lett 6(4). doi:10.1088/1748-9326/6/4/049001

Morton TA, Rabinovich A, Marshall T, Bretschneider P (2011) The future that may (or may not) come: how framing changes responses to uncertainty in climate change communications. Glob Environ Chang 21(1): 103-109

Nerlich B, Jaspal R (2012) Metaphors we die by? Geoengineering, metaphors, and the argument from catastrophe. Metaphor Symb 27(2):131-147

Nisbet MC, Brossard D, Kroepsch A (2003) Framing science: the stem cell controversy in an age of press/ politics. Press/Politics 8:36-70

Parkhill KA, Pidgeon NF, Corner A, Vaughan N (2013) Deliberation and responsible innovation: a geoengineering case study'. In: Owen R, Bessant J, Heintz M (eds) Responsible innovation. Wiley, London, pp 219-239

Pidgeon N, Harthorn BH, Bryant K, Rogers-Hayden T (2009) Deliberating the risks of nanotechnologies for energy and health applications in the United States and United Kingdom. Nat Nanotechnol 4:95-98

Rogers-Hayden T, Pidgeon N (2007) Moving engagement "upstream"? Nanotechnologies and the Royal Society and Royal Academy of Engineering inquiry. Public Underst Sci 16:346-364

Pidgeon N, Parkhill KA, Corner A, Vaughan N (2013) Deliberating stratospheric aerosols for climate geoengineering: the case of the UK SPICE project. Nat Clim Chang. http://www.nature.com/doifinder/10. 1038/nclimate 1807

Pope FD, Braesicke P, Grainger R, Kalberer M, Watson IM, Davidson P, Cox R (2012) Stratospheric aerosol particles and solar radiation management. Nat Clim Chang 2:713-719

Porter K, Hulme M (2013) The emergence of the geoengineering debate in the UK print media: a frame analysis. The Geographical Journal

Preston C (2012) Beyond the end of nature: SRM and two tales of artificiality for the anthropocene. Ethics Policy Environ 15(2):188-201

Royal Society (2009) Geoengineering the climate: science, governance and uncertainty. science policy centre report 10/09. The Royal Society, London

Scholte S, Vasileiadou E, Petersen AC (2013) Opening up the societal debate on climate engineering: how newspaper frames are changing. J Integr Environ Sci. doi:10.1080/1943815X.2012.759593

Schwartz SH (1992) Universals in the content and structure of values: theoretical advances and empirical tests in 20 countries. In: Zanna MP (ed) Advances in experimental social psychology, vol 25. Academic, San Diego, pp $1-65$

Sikka T (2012) A critical discourse analysis of geoengineering advocacy. Crit Discourse Stud 9(2):163-175

Slovic P (2000) The perception of risk. Earthscan, London

Stilgoe J (2011) A question of intent. Nat Clim Chang 1:325-326

Stilgoe J, Owen R, Macnaghten P (2014) Developing a framework for responsible innovation. Res Policy 42: $1568-1580$ 
Stirling A (2008) Opening up and closing down: power, participation and pluralism in the social appraisal of technology. Sci Technol Hum Values 33:262-294

Vaughan NE, Lenton TM (2011) A review of climate geoengineering proposals. Clim Chang 109:745-790

Walls J, Rogers-Hayden T, Mohr A, O'Riordan T (2005) Seeking citizens' views on GM Crops-experiences from the United Kingdom, Australia, and New Zealand. Environment 47(7):22-36

Wilsdon J, Willis R (2004) See-through science: why public engagement needs to move upstream. Demos, London Whitmarsh L (2011) Scepticism and uncertainty about climate change: dimensions, determinants and change over time. Glob Environ Chang 21(2):690-700 